\title{
Perustamislannoitus antaa potkua ruokohelvelle
}

Elina Virkkunen ${ }^{1)}$, Kalle Hoppula ${ }^{1)}$, Olli Reinikainen ${ }^{2)}$, Raimo Kauppila ${ }^{3)}$, Jukka Kemppainen ${ }^{1)}$ ja Vesa Järvelin ${ }^{1)}$

${ }^{1)}$ MTT Sotkamo, Kipinäntie 16, 88600 Sotkamo, etunimi.sukunimi@mtt.fi

${ }^{2)}$ Vapo Oy, PL 22, 40101 Jyväskylä, etunimi.sukunimi@vapo.fi

${ }^{3)}$ Yara Suomi Oy, PL 900, 00181 Helsinki, etunimi.sukunimi@yara.com

\section{Tiivistelmä}

MTT Sotkamon tutkimusasema toteutti yhteistyössä Vapon ja Yara Suomen kanssa vuosina 2005 2008 ruokohelven lannoitus- ja kalkituskokeen, jossa tutkittiin rakeisten Y-lannoitteiden, hivenlisäyksen, lietekompostin, biotiitin ja Siilinjärven magnesiumpitoisen kalkin vaikutuksia ruokohelven kasvuun.

Ruokohelven lannoituskoe perustettiin vuonna 2005 runsasmultaiselle hietamoreenimaalle. Kokeesta tehtiin kasvumittaukset elokuussa 2006 sekä satomittaukset toukokuussa 2007 ja toukokuussa 2008. Koejäseniä oli 7:

1 kalkitus dolomiittikalkilla, suositusten mukainen lannoitus

2 kalkitus dolomiittikalkilla, suositusten mukainen lannoitus, hivenlannoitus

3 ei lannoitusta

4 biotiitti, suositusten mukainen lannoitus

5 kaksinkertainen määrä biotiittia, suositusten mukainen lannoitus

6 dolomiittikalkki, lietekomposti

7 biotiitti, lietekomposti

Perustamisen jälkeisenä vuonna lannoittamaton käsittely kasvoi muita heikommin, samoin toisena vuonna. Kolmantena vuonna koetta ei lannoitettu, ja erot tasoittuivat entisestään. Siinä mielessä hidasliukoiset komposti ja biotiittikaan eivät olleet muita lannoitteita parempia. Eri biotiittilannoitusmäärien välillä ei ollut eroja.

Viljavuusanalyysin perusteella maassa oli rikkiä, kuparia, mangaania ja sinkkiä riittävästi. Tämän johdosta erillinen hivenlannoitus ei vaikuttanut sadon määrään.

Kokeessa ei saatu eri lannoituskäsittelyjen välille merkitseviä eroja, vaikka lannoittamaton ruutu erottui muita heikompana. Tämän kokeen perusteella vaikuttaisi siltä, että lannoiteaineella ei ole merkitystä, kunhan ruokohelpi saa jollakin tavoin tarvitsemansa ravinteet.

Vuonna 2006 koejäsenten hehtaaria kohti lasketut kuiva-ainesadot vaihtelivat välillä 5316-7248 kg/ha ja vuonna 2007 välillä 6205-7057 kg/ha. Vastaavat tuoresadot vaihtelivat vuonna 2006 63339033 kg/ha ja vuonna 2007 välillä 7683-9967 kg/ha. Lisäksi kokeessa mitattiin vuonna 2006 kasvuston korkeus ja ylimmän lehden korkeus sekä laskettiin verojen määrä neliömetrillä.

Ruokohelven viljelystä saatava tulo perustuu suurimmilta osin tukiin. Näin ollen viljelijän kannattaa käyttää edullisinta lannoitetta, jolla kasvuston ravinnetarve saadaan tyydytettyä. Kemiallisten lannoitteiden kallistuminen parantaa kotoperäisten lannoitteiden, kuten karjanlannan ja kompostin, kilpailuetua. Kokeessa jouduttiin tyytymään pieniin kompostilannoitemääriin. Uusi lannoitevalmistelaki ottaa paremmin huomioon kompostin ravinteiden hitaan liukoisuuden.

\section{Avainsanat}

ruokohelpi, Phalaris arundinacea, lannoitus, hivenlannoitus, kalkitus 


\section{Johdanto}

Ruokohelpi on 2000-luvulla noussut Suomessa merkittävimmäksi energiakasviksi. MTT Sotkamon tutkimusasema toteutti yhteistyössä Vapon ja Yara Suomen kanssa vuosina 2005 - 2008 ruokohelven lannoitus- ja kalkituskokeen, jossa tutkittiin rakeisten Y-lannoitteiden, hivenlisäyksen, lietekompostin, biotiitin ja Siilinjärven magnesiumpitoisen kalkin vaikutuksia ruokohelven kasvuun. Ruokohelven hivenlannoitusta ei aiemmin Suomessa oltu tutkittu. Koesuunnittelu lähti tutkimuksen yhteistyöyritysten tarpeista.

\section{Aineisto ja menetelmät}

Ruokohelven lannoituskoe perustettiin 6.7.2005 MTT Sotkamon tutkimusaseman pellolle. Pellon maalaji oli runsasmultainen hietamoreeni, jonka viljavuusanalyysin mukaiset ominaisuudet olivat koetta perustettaessa seuraavat: pH 5,5-5,7, Ca 940-1200 mg/l, P 4,9-6,2 mg/l, K 43,1-54,6, Mg 106-147 mg/l, S 16-18 mg/l, B 0,3-0,4 mg/l, Cu 6,8-7,5 mg/l, Mn 30-54 ja Zn 1,43-2,86 mg/l.

Kokeessa käytetyt lannoitus- ja kalkitusaineet käyttömäärineen on kuvattu taulukossa 1 . Vuonna 2005 kokeen perustamisen yhteydessä annetut ravinnemäärät on esitelty taulukossa 2 ja vuonna 2006 annetut ravinnemäärät on esitelty taulukossa 3. Vuodesta 2007 alkaen koetta ei enää lannoitettu.

Kokeesta tehtiin kasvumittaukset elokuussa 2006 sekä satomittaukset toukokuussa 2007 ja toukokuussa 2008. Vuoden 2006 kasvumittauksissa havainnoitiin ruokohelven röyhyjen lukumäärä $\left(\mathrm{kpl} / \mathrm{m}^{2}\right)$, kasvuston kokonaiskorkeus (cm), kasvuston korkeus ylimmän lehden juureen saakka $(\mathrm{cm}) \mathrm{ja}$ korsien lukumäärä $\left(\mathrm{kpl} / \mathrm{m}^{2}\right)$. Vuosien 2007 ja 2008 satomittauksissa havainnoitiin tuoresato $(\mathrm{kg} / \mathrm{ha}) \mathrm{ja}$ kuivasato (kg/ha) sekä näiden perusteella laskettu kuiva-ainepitoisuus. Kokeen päätyttyä kesäkuussa 2008 kustakin käsittelystä otettiin viljavuusanalyysi.

Tulosten tilastollinen analyysi tehtiin SAS 9.1 -tilasto-ohjelmiston MIXED -proseduuria käyttäen.

Taulukko 1. Kokeessa käytetyt lannoitus- ja kalkitusaineet käyttömäärineen (kg/ha).

\begin{tabular}{lll}
\hline Vuosi & Käsittely & Lannoitus- ja kalkitusaineet (sulkeissa aineen alkuperä) sekä käyttömäärät \\
\hline 2005 & 1 & Syysviljan Y1 (Kemira GrowHow) $460 \mathrm{~kg} / \mathrm{ha}$ \\
2005 & 1 & Siilinjärven Mg-pitoinen kalkki (Kemira GrowHow) $11200 \mathrm{~kg} / \mathrm{ha}$ \\
2005 & 2 & Syysviljan Y1 (Kemira GrowHow) $460 \mathrm{~kg} / \mathrm{ha}$ \\
2005 & 2 & Siilinjärven Mg-pitoinen kalkki (Kemira GrowHow) $11200 \mathrm{~kg} / \mathrm{ha}$ \\
2005 & 2 & Hivenravinneseos (Kemira GrowHow) $350 \mathrm{~kg} / \mathrm{ha}$ \\
2005 & 3 & Ei lannoitusta \\
2005 & 4 & Syysviljan Y1 (Kemira GrowHow) $460 \mathrm{~kg} / \mathrm{ha}$ \\
2005 & 4 & Pellon Biotiitti (Kemira GrowHow) $5000 \mathrm{~kg} / \mathrm{ha}$ \\
2005 & 5 & Syysviljan Y1 (Kemira GrowHow) $460 \mathrm{~kg} / \mathrm{ha}$ \\
2005 & 5 & Pellon Biotiitti (Kemira GrowHow) $10000 \mathrm{~kg} / \mathrm{ha}$ \\
2005 & 6 & Himangan lietekomposti (Vapo) $12200 \mathrm{~kg} / \mathrm{ha}$ \\
2005 & 6 & Siilinjärven Mg-pitoinen kalkki (Kemira GrowHow) $11200 \mathrm{~kg} / \mathrm{ha}$ \\
2005 & 7 & Pellon Biotiitti (Kemira GrowHow) $10000 \mathrm{~kg} / \mathrm{ha}$ \\
2005 & 7 & Himangan lietekomposti (Vapo) $12200 \mathrm{~kg} / \mathrm{ha}$ \\
& \\
2006 & 1 & Kevätviljan Y6 (Kemira GrowHow) $370 \mathrm{~kg} / \mathrm{ha}$ \\
2006 & 2 & Kevätviljan Y6 (Kemira GrowHow) $370 \mathrm{~kg} / \mathrm{ha}$ \\
2006 & 3 & Ei lannoitusta \\
2006 & 4 & Nurmen Y2 (Kemira GrowHow) $310 \mathrm{~kg} / \mathrm{ha}$ \\
2006 & 5 & Nurmen Y2 (Kemira GrowHow) $310 \mathrm{~kg} / \mathrm{ha}$ \\
2006 & 6 & Syysviljan Y1 (Kemira GrowHow) $330 \mathrm{~kg} / \mathrm{ha}$ \\
2006 & 7 & Nurmen Y2 (Kemira GrowHow) $230 \mathrm{~kg} / \mathrm{ha}$ \\
\hline
\end{tabular}


Taulukko 2. Eri lannoituskäsittelyjen saamat ravinnemäärät (kg/ha) kokeen perustamisen yhteydessä vuonna 2005.

\begin{tabular}{llllllllllllll}
\hline Käsittely & $\mathrm{N}$ & $\mathrm{P}$ & $\mathrm{K}$ & $\mathrm{Ca}$ & $\mathrm{Mg}$ & $\mathrm{S}$ & $\mathrm{B}$ & $\mathrm{Cu}$ & $\mathrm{Fe}$ & $\mathrm{Mn}$ & $\mathrm{Mo}$ & $\mathrm{Zn}$ & $\mathrm{Se}$ \\
\hline 1 & 59,8 & 32,2 & 59,8 & 3373,8 & 338,3 & 13,8 & 0,092 & 0 & 0 & 0 & 0 & 0,46 & 0,0046 \\
2 & 59,8 & 32,2 & 59,8 & 3412,3 & 355,8 & 73,3 & 1,142 & 3,5 & 1,05 & 7 & 0,175 & 3,26 & 0,0046 \\
3 & 0 & 0 & 0 & 0 & 0 & 0 & 0 & 0 & 0 & 0 & 0 & 0 & 0 \\
4 & 59,8 & 32,2 & 309,8 & 363,8 & 502,3 & 13,8 & 0,092 & 0 & 0 & 0 & 0 & 0,46 & 0,0046 \\
5 & 59,8 & 32,2 & 559,8 & 713,8 & 1002,3 & 13,8 & 0,092 & 0 & 0 & 0 & 0 & 0,46 & 0,0046 \\
6 & 61 & 36,6 & 61 & 3360 & 340,9 & 0 & 0 & 0 & 0 & 0 & 0 & 0 & 0 \\
7 & 61 & 36,6 & 561 & 700 & 1004,9 & 0 & 0 & 0 & 0 & 0 & 0 & 0 & 0 \\
\hline
\end{tabular}

Taulukko 3. Eri lannoituskäsittelyjen saamat ravinnemäärät (kg/ha) vuonna 2006.

\begin{tabular}{llllllllllllll}
\hline Käsittely & $\mathrm{N}$ & $\mathrm{P}$ & $\mathrm{K}$ & $\mathrm{Ca}$ & $\mathrm{Mg}$ & $\mathrm{S}$ & $\mathrm{B}$ & $\mathrm{Cu}$ & $\mathrm{Fe}$ & $\mathrm{Mn}$ & $\mathrm{Mo}$ & $\mathrm{Zn}$ & $\mathrm{Se}$ \\
\hline 1 & 62,9 & 14,8 & 48,1 & 0 & 1,85 & 7,4 & 0,074 & 0 & 0 & 0 & 0 & 0 & 0,0037 \\
2 & 62,9 & 14,8 & 48,1 & 0 & 1,85 & 7,4 & 0,074 & 0 & 0 & 0 & 0 & 0 & 0,0037 \\
3 & 0 & 0 & 0 & 0 & 0 & 0 & 0 & 0 & 0 & 0 & 0 & 0 & 0 \\
4 & 62 & 15,5 & 21,7 & 0 & 1,55 & 9,3 & 0,062 & 0 & 0 & 0 & 0 & 0,31 & 0,0031 \\
5 & 62 & 15,5 & 21,7 & 0 & 1,55 & 9,3 & 0,062 & 0 & 0 & 0 & 0 & 0,31 & 0,0031 \\
6 & 42,9 & 23,1 & 42,9 & 9,9 & 1,65 & 9,9 & 0,066 & 0 & 0 & 0 & 0 & 0,33 & 0,0033 \\
7 & 46 & 11,5 & 16,1 & 0 & 1,15 & 6,9 & 0,046 & 0 & 0 & 0 & 0 & 0,23 & 0,0023 \\
\hline
\end{tabular}

\section{Tulokset ja tulosten tarkastelu}

Vuonna 2006 eli vuosi perustamisen jälkeen tehdyissä kasvustomittauksissa lannoittamaton käsittely 3 menestyi heikoimmin. Parhaimmin menestyivät käsittelyt 1, 4, 5 ja 7 eli biotiittia saaneet käsittelyt 4,5 ja 7 sekä Syysviljan Y1 -lannosta ilman hivenravinnelisää saanut käsittely 1.

Ensimmäisenä satovuonna, 2007, lannoittamaton käsittely erottui muita heikompana, mutta muiden käsittelyjen välillä ei ilmennyt tilastollisesti merkitseviä eroja. Vuonna 2007 koetta ei lainkaan lannoitettu ja siksi satomittauksissa keväällä 2008 käsittelyjen väliset erot olivat tasoittuneet ja tilastollisesti merkitseviä eroja ei ilmennyt lainkaan.

Ennen kokeen perustamista tehdyn viljavuusanalyysin mukaan pellon fosforiluokka oli välttävä, kaliumluokka huononlainen ja happamuus välttävä, mikä oli hyvä lähtötilanne lannoitus- ja kalkitustutkimukselle. Siitä huolimatta kokeessa ei eri lannoituskäsittelyjen välille saatu merkitseviä eroja. Ainoastaan lannoittamaton käsittely erosi muita huonompana. Myöskään yhtenä vuonna lannoittamatta jättäminen ei tuonut käsittelyjen välille eroja, vaan päinvastoin tasoitti niitä. Siinä mielessä hidasliukoiset komposti ja biotiittikaan eivät olleet muita lannoitteita parempia.

Viljavuusanalyysin perusteella maassa oli rikkiä, kuparia, mangaania ja sinkkiä riittävästi. Tämän johdosta erillinen hivenlannoitus ei vaikuttanut sadon määrään. Maan booripitoisuus oli hyvin vähäinen, mutta Y-lannoitteiden sisältämä boori näytti riittävän kasvuston tarpeisiin.

Tässä kokeessa sadontuottoa seurattiin vain toiseen sadonkorjuuseen saakka. Samasta ruokohelpikasvustosta otetaan kuitenkin satoa huomattavasti kauemmin ja on mahdollista, että hidasliukoisten lannoiteaineiden, biotiitin ja kompostin, vaikutus olisi myöhemmin voinut jollain tavoin tulla esille. Yllättävää on, että biotiitin eri levitysmäärien välillä ei ollut satoeroja. Kokeen päätyttyä tehdyssä viljavuusanalyysissa biotiittia saaneissa käsittelyissä 4, 5 ja 7 maan kaliumpitoisuus oli muita suurempi, mutta koska tämä ei näkynyt sadossa, on joku muu tekijä ollut sadontuoton minimitekijänä. Myöskään maan happamuusvaihtelu välillä 5,7 - 6,2 ei tässä kokeessa ollut ratkaiseva tekijä.

Taulukko 4. Ruokohelven röyhyjen lukumäärä $\left(\mathrm{kpl} / \mathrm{m}^{2}\right)$, kasvuston kokonaiskorkeus $(\mathrm{cm})$ ja kasvuston korkeus ylimmän lehden juureen saakka (cm) 21.8.2006 sekä tulosten tilastollista merkitsevyyttä kuvaavat p-arvot. Samalla vaakarivillä samalla kirjaimella merkityt arvot eivät tilastollisesti eroa toisistaan. 


\begin{tabular}{lllllllll}
\hline \multicolumn{3}{c}{ Käsittely } & & & & & & \\
& 1 & 2 & 3 & 4 & 5 & 6 & 7 & p-arvo \\
\hline Röyhyt $(\mathrm{kpl} / \mathrm{m} 2)$ & $114 \mathrm{~b}$ & $92 \mathrm{~b}$ & $53 \mathrm{a}$ & $105 \mathrm{~b}$ & $90 \mathrm{~b}$ & $89 \mathrm{~b}$ & $92 \mathrm{~b}$ & $<0,0001$ \\
Kokonaiskork. $(\mathrm{cm})$ & $173 \mathrm{bc}$ & $170 \mathrm{~b}$ & $155 \mathrm{a}$ & $176 \mathrm{bc}$ & $182 \mathrm{c}$ & $169 \mathrm{~b}$ & $171 \mathrm{bc}$ & $<0,0001$ \\
Korkeus yl.lehd. $(\mathrm{cm})$ & $136 \mathrm{ab}$ & $136 \mathrm{ab}$ & $128 \mathrm{a}$ & $136 \mathrm{ab}$ & $138 \mathrm{~b}$ & $131 \mathrm{ab}$ & $137 \mathrm{ab}$ & 0,0117 \\
\hline
\end{tabular}

Taulukko 5. Ruokohelven satotasot (kg/ha) ja kuiva-ainepitoisuus (g kuivamassaa / kg tuoremassaa) Sotkamossa 3.5.2007 sekä tulosten tilastollista merkitsevyyttä kuvaavat p-arvot. Samalla vaakarivillä samalla kirjaimella merkityt arvot eivät tilastollisesti eroa toisistaan.

\begin{tabular}{|c|c|c|c|c|c|c|c|c|}
\hline & \multicolumn{8}{|c|}{ Käsittely } \\
\hline & 1 & 2 & 3 & 4 & 5 & 6 & 7 & p-arvo \\
\hline Kuiva-ainepitoisuus (g/kg) & $806 a$ & $812 a$ & $837 a$ & $830 a$ & $880 a$ & $825 a$ & $812 a$ & 0,4458 \\
\hline Tuoresato $(\mathrm{kg} / \mathrm{ha})$ & $9033 b$ & $8650 \mathrm{~b}$ & 6333a & $8300 b$ & $7767 b$ & $7967 b$ & $8167 b$ & 0,0572 \\
\hline Kuivasato (kg/ha) & $7248 b$ & $7023 b$ & $5316 a$ & $6858 b$ & $6436 b$ & $6567 b$ & $6603 b$ & 0,0828 \\
\hline
\end{tabular}

Taulukko 6. Ruokohelven satotasot (kg/ha) ja kuiva-ainepitoisuus (g kuivamassaa / kg tuoremassaa) Sotkamossa 6.5.2008 sekä tulosten tilastollista merkitsevyyttä kuvaavat p-arvot. Tilastollisia eroja ei ole esitetty, koska sellaisia ei esiintynyt.

\begin{tabular}{|c|c|c|c|c|c|c|c|c|}
\hline & \multicolumn{8}{|c|}{ Käsittely } \\
\hline & 1 & 2 & 3 & 4 & 5 & 6 & 7 & p-arvo \\
\hline Kuiva-ainepitoisuus (g/kg) & 647 & 743 & 817 & 780 & 753 & 741 & 762 & 0,1998 \\
\hline Tuoresato kg/ha & 9967 & 9417 & 7683 & 8850 & 8267 & 8883 & 9267 & 0,1113 \\
\hline Kuivasato kg/ha & 6358 & 6931 & 6278 & 6836 & 6205 & 6464 & 7057 & 0,3405 \\
\hline
\end{tabular}

Taulukko 7. Viljavuusanalyysin tulokset kokeen päätyttyä 17.6.2009.

\begin{tabular}{llllllll}
\hline & Käsittely & & & & & \\
& 1 & 2 & 3 & 4 & 5 & 6 & 7 \\
\hline Johtoluku (10 x mS/cm) & 1,1 & 1,1 & 0,8 & 0,8 & 0,9 & 1,1 & 0,9 \\
Pintamaan happamuus (pH) & 6,2 & 6,1 & 5,7 & 5,7 & 5,7 & 6,1 & 5,8 \\
Ca (mg/l) & 1690 & 1420 & 950 & 874 & 971 & 1550 & 1040 \\
P (mg/l) & 4,6 & 4,5 & 4,3 & 4,4 & 4,6 & 4,8 & 4,8 \\
K (mg/l) & 44 & 43 & 38 & 60 & 83 & 38 & 66 \\
Mg (mg/l) & 130 & 120 & 110 & 97 & 110 & 120 & 110 \\
S (mg/l) & 12 & 14 & 13 & 13 & 13 & 14 & 14 \\
B (mg/l) & 0,4 & 0,4 & 0,4 & 0,4 & 0,3 & 0,3 & 0,3 \\
Cu (mg/l) & 6,1 & 6,8 & 6,3 & 6,1 & 6,5 & 6,4 & 6,8 \\
Mn & 14 & 15 & 23 & 23 & 25 & 14 & 23 \\
Zn (mg/l) & $<1,0$ & 1,1 & 1,0 & 1,0 & $<1,0$ & 1,3 & 1,7 \\
Fe (mg/l) & 690 & 730 & 810 & 790 & 800 & 720 & 810 \\
\hline
\end{tabular}




\section{Johtopäätökset}

Kokeessa ei saatu eri lannoituskäsittelyjen välille merkitseviä eroja. Ainoastaan lannoittamaton käsittely menestyi muita käsittelyjä heikommin. Tämän kokeen perusteella vaikuttaisi siltä, että lannoiteaineella ei ole biologista merkitystä, kunhan ruokohelpi saa jollakin tavoin tarvitsemansa ravinteet.

Ruokohelven viljelystä saatava tulo perustuu suurimmilta osin tukiin. Näin ollen viljelijän kannattaa käyttää edullisinta lannoitetta, jolla kasvuston ravinnetarve saadaan tyydytettyä. Kemiallisten lannoitteiden kallistuminen parantaa kotoperäisten lannoitteiden, kuten karjanlannan ja kompostin, kilpailuetua.

Kokeessa jouduttiin tyytymään pieniin kompostilannoitemääriin. Uusi lannoitevalmistelaki ottaa paremmin huomioon kompostin ravinteiden hitaan liukoisuuden. 